\title{
Installation of Centrifugal Casting of Aluminum Cast Iron in the Process of Self-Spreading High-Temperature Synthesis \\ ${ }^{1}$ Artur M. Mingaleev, ${ }^{2}$ Nikolay N. Safronov, ${ }^{3}$ Lenar R. Kharisov \\ ${ }^{1-3}$ Kazan Federal University \\ Email:ln271@mail.ru
}

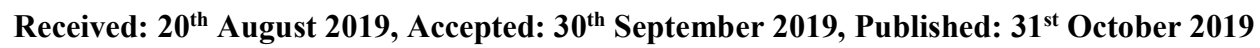

\begin{abstract}
The article proposes a technology for producing castings from aluminum cast iron with an aluminum content of 10 ... $19 \%$ by centrifugal SHS casting, which is an environmentally friendly production and ensures the production of castings with high mechanical properties for structural materials. Due to the structural features of aluminum cast irons, they have high hardness and fragility, which is why they are unsuitable as a structural material. However, in view of the low density, which is $5600 \ldots 6000 \mathrm{~kg} / \mathrm{m}^{3}$, its use for cast parts helps to reduce their mass, which has a positive effect on the quality of automotive products. In addition, the discussed aluminum cast iron has heat resistance and wear resistance. It is proposed to use self-propagating high temperature synthesis (SHS) to produce aluminum cast iron. As starting materials, dispersed wastes of the forge and foundry of KamAZ PJSC were used. To clean the blacksmith scale and aluminum shavings and ensure the necessary dispersion, a vibrating screen was designed, as well as a centrifugal casting unit for the SHS process. A centrifugal casting plant with a vertical axis of rotation, in the drum of which six graphite reactors were insulated with asbestos and nichrome thread for further annealing.
\end{abstract}

\section{Keywords}

Centrifugal Casting, Cast Iron, Aluminum, Shavings, Scale, Self-Spreading High-Temperature Synthesis.

\section{Introduction}

The object of study is aluminum cast iron containing 10-19\% aluminum. A feature of such aluminum cast irons is that they crystallize in a mold using a metastable mechanism, i.e., in its structure, carbon is in a bound state. The structure of these aluminum cast irons consists of two phases, namely: aluminum-doped ferrite and $\gamma^{\prime}$ phase, which is a carbide-type compound $\mathrm{Fe}_{3} \mathrm{AlC}_{\mathrm{X}}$. These phases are characterized by high hardness. The microhardness of ferrite is HV 360-400, and the microhardness of the $\gamma^{\prime}$ phase is even greater than HV 640-850. The amount of $\gamma^{\prime}$ phase depends on the content of aluminum and carbon [1].

Due to the structural features of aluminum cast irons, they have high hardness and fragility, which is why they are unsuitable as a structural material. However, in view of the low density, which is $5600 \ldots 6000 \mathrm{~kg} / \mathrm{m}^{3}$, its use for cast parts helps to reduce their mass, which has a positive effect on the quality of automotive products. In addition, the discussed aluminum cast iron has heat resistance and wear resistance [2].

\section{Problem Statement}

Traditionally, molten aluminum cast iron is smelted in high-frequency induction furnaces with a main lining. Pig iron and steel scrap are loaded into the furnace. After the charge is melted, the liquid metal is brought to a temperature of 1450 $1500^{\circ} \mathrm{C}$ and alloyed with cast aluminum. In order to reduce the burning of aluminum, it is introduced deep into the liquid metal by recessing it into the furnace until it is completely dissolved. Thus, the technological process of preparing the melt and obtaining castings from it includes a large number of operations, significant energy costs, a large range of materials, labor resources, the use of complex and expensive equipment [3]. Moreover, achieving the required quality of castings is often problematic and unstable.

\section{Experimental Procedures}

To eliminate these drawbacks, it is proposed to use self-propagating high-temperature synthesis (SHS) to produce aluminum cast iron [4-8]. For experiments, dispersed wastes of the forge and foundry of KamAZ PJSC were used. A vibrating screen was designed to clean the blacksmith scale and aluminum chips from foreign impurities and ensure the necessary dispersion (Fig. 1) [9]. 


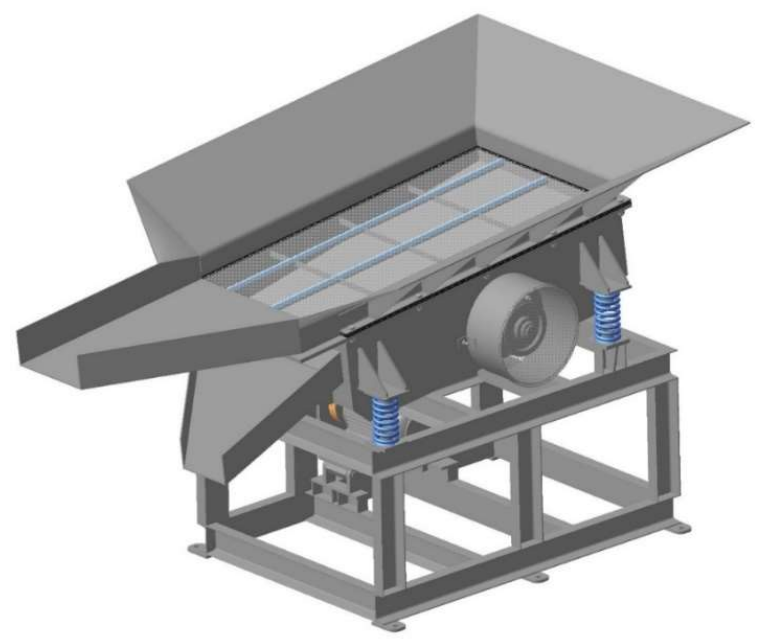

Figure 1: Vibrating Screen

The first sieve passes only the scale, and the garbage leaves through the tray. The second sieve controls the required dispersion of the scale, i.e. suitable dross is crumbled into the drive, and larger fractions move into the tray. Subsequently, they are ground using a ball mill and again passed through a vibrating screen. Similarly to the principle, aluminum chips are cleaned and ground. The crushed components are placed in a rotating drum to obtain a homogeneous mixture.

\begin{tabular}{|c|c|c|c|c|c|c|}
\hline \multicolumn{2}{|c|}{ Blacksmith } & \multicolumn{5}{c|}{ Aluminum chips (D16)\% } \\
\hline Magnetite $\mathrm{Fe}_{3} \mathrm{O}_{4}, \%$ & Hematite $\mathrm{Fe}_{2} \mathrm{O}_{3}, \%$ & $\mathrm{Cu}$ & $\mathrm{Mn}$ & $\mathrm{Mg}$ & $\mathrm{Si}$ & $\mathrm{Fe}$ \\
\hline 35 & 65 & $3.2-4.5$ & $0.3-0.9$ & $1.2-1.8$ & 0.5 & 0.5 \\
\hline
\end{tabular}

\section{Table 1: The Composition of the Main Charge Elements of the SHS Process}

The amount of aluminum for descaling (1000 gr.) Is calculated by the formulas:

$\mathrm{Fe}_{2} \mathrm{O}_{3}+2 \mathrm{Al}=2 \mathrm{Fe}+\mathrm{Al}_{2} \mathrm{O}_{3}$

$n\left(\mathrm{Fe}_{2} \mathrm{O}_{3}\right)=m / M=1000 / 159,7=6,262 \mathrm{~mol}$

$n(\mathrm{Al})=n\left(\mathrm{Fe}_{2} \mathrm{O}_{3}\right) \times 2 / 1=6,3 \times 2 / 1=12,6 \mathrm{~mol}$

$m(A l)=n \times M=12,6 \times 27=3382$.

Thus, $33.8 \%$ of aluminum is required for the complete reduction of iron.

\begin{tabular}{|c|c|c|c|}
\hline Aluminum Cast Iron Al, \% & Blacksmith, \% & Aluminum chips (D16), \% & Powdered graphite, $\%$ \\
\hline 10 & $67-68.5$ & $30.1-30.8$ & $1.4-2.3$ \\
\hline 14 & $65-67$ & $30.8-32$ & $2,3-2,6$ \\
\hline 19 & $62-66$ & $32.5-34.4$ & $2.6-3.1$ \\
\hline
\end{tabular}

Table 2: The Composition of the Mixture of the SHS Process for Producing Aluminum Cast Iron.

The proposed technology combines two processes: centrifugal casting and casting in the SHS process. Upon receipt of castings by SHS casting in graphite form, a number of disadvantages were revealed:

- partial separation of the metal and slag phase;

- the appearance of casting defects in the form of sieve porosity and gas shells;

- the low surface quality of the resulting castings;

- increased hardness and excessive brittleness due to the fact that carbide inclusions of the $\gamma^{\prime}$ phase $\left(\mathrm{Fe}_{3} \mathrm{AlC} \mathrm{C}_{\mathrm{x}}\right)$ were present in the structure, which led to a deterioration in machinability by cutting.

After a series of experiments, the dependence of the change in the quality of the obtained castings on the increase in the mass of the mixture was revealed. The increase in reactor volume reduced heat loss during the smelting process, and it became possible to get rid of most of the disadvantages of this technology. But the problem of obtaining small castings remained relevant. It was decided to make small castings by centrifugal SHS casting. A centrifugal casting plant with a vertical axis of rotation, in the drum of which six graphite reactors were insulated with asbestos and nichrome thread for further annealing. When the centrifugal machine starts up, voltage is applied to the nichrome thread through slip rings to heat the mold, then the SHS process is initiated, which takes 35-45 seconds. After the drum stops, voltage is again applied to the thread for the annealing process, which is carried out at a temperature of $1000^{\circ} \mathrm{C}$. The synthesis process proceeds with the release of a large amount of heat, which is enough to heat the charge materials and transfer them into a liquid state with overheating up to $2200-2400^{\circ} \mathrm{C}$. In this case, two liquid phases are formed: the synthesized aluminum cast iron and the slag phase in the form of fused corundum. 
Calculation of the thermal effect:

$m\left(\mathrm{Fe}_{2} \mathrm{O}_{3}\right)=4000 \mathrm{gr}$.

$Q=19040 \mathrm{~kJ}$

$\mathrm{Fe}_{2} \mathrm{O}_{3}+\mathrm{Al}=\mathrm{Al}_{2} \mathrm{O}_{3}+\mathrm{Fe}+\mathrm{QP}_{\mathrm{P}}$

$n\left(\mathrm{Fe}_{2} \mathrm{O}_{3}\right)=m\left(\mathrm{Fe}_{2} \mathrm{O}_{3}\right) / \mathrm{M}\left(\mathrm{Fe}_{2} \mathrm{O}_{3}\right)=4000 / 160=25 \mathrm{~mol}$

$Q_{P}=Q / n\left(\mathrm{Fe}_{2} \mathrm{O}_{3}\right)=19040 / 25=761.6 \mathrm{~kJ} / \mathrm{mol}$

\section{Results and Discussion}

The initiation of the SHS process is achieved by heating granular magnesium mixed with potassium nitrate with a nichrome thread through which electric current is passed through slip rings. Upon initiation and occurrence of the SHS process, centrifugal force prevents the spraying of reaction products. In addition, it contributes to the complete separation of the metal and slag phase. The resulting slag layer reliably protects the synthesized molten aluminum cast iron from exposure to air, which prevents foaming in the casting. The process of synthesizing aluminum cast iron proceeds with high overheating of the liquid melt, which contributes to its homogenization. The duration of the SHS process and crystallization, in view of the high thermal activity of the graphite form, proceeds incomparably faster compared to traditional melting methods. After crystallization of the liquid products of the SHS process, the rotation of the centrifugal installation stops and the heating element of the reactors is turned on, which maintains the temperature in the reactor at the level of $900-1000^{\circ} \mathrm{C}$. This contributes to the decomposition of carbide inclusions of the $\gamma^{\prime}$-phase $\left(\mathrm{Fe}_{3} \mathrm{AlC} \mathrm{C}_{\mathrm{X}}\right)$ with the formation of compact form graphite inclusions. The amount of the $\gamma$ 'phase depends on the content of $\mathrm{Al}$ and $\mathrm{C}$. In alloys containing $11 \ldots 14 \% \mathrm{Al}$, ferrite is paramagnetic, the $\gamma$ 'phase is ferromagnetic. At $19 \% \mathrm{Al}$, cast iron has a paramagnetic single-phase ferrite matrix [10].

\begin{tabular}{|c|c|c|c|c|c|c|c|c|}
\hline \multicolumn{6}{|c|}{ Aluminum cast iron $(\%)$} & \multicolumn{3}{|c|}{ Fused Corundum $(\%)$} \\
\hline $\mathrm{C}$ & $\mathrm{Si}$ & $\mathrm{Al}$ & $\mathrm{Mn}$ & $\mathrm{P}$ & $\mathrm{S}$ & $\mathrm{Al}_{2} \mathrm{O}_{3}$ & $\mathrm{Fe}_{2} \mathrm{O}_{3}$ & $\mathrm{C}$ \\
\hline $1.8-2$ & $0.8-1.2$ & 10 & $0.2-0.6$ & $0.2-0.3$ & $0.03-0.08$ & 98.3 & 0.8 & 0.5 \\
\hline $2-2.2$ & $0.9-1.2$ & 14 & $0.3-0.8$ & $0.2-0.3$ & $0.03-0.08$ & 98.5 & 0.5 & 0.9 \\
\hline $2.2-2.6$ & $0.9-1.2$ & 19 & $0.3-0.9$ & $0.15-0.2$ & 0.04-0.09 & 98.8 & 0.6 & 0.6 \\
\hline
\end{tabular}

Table 3: The Chemical Composition of SHS Synthesis Products.

\begin{tabular}{|c|c|c|c|}
\hline $\mathrm{Al}$ content, $\%$ & Ultimate ensile strength, $\mathrm{MPa}$ & flexural strength & Microhardness, HV \\
\hline 10 & $98-147$ & $176-275$ & $280-320$ \\
\hline 14 & $98-137$ & $166-215$ & $320-350$ \\
\hline 19 & $78-118$ & $147-186$ & $360-540$ \\
\hline
\end{tabular}

Table 4: Mechanical Properties of Aluminum Cast Iron

A centrifugal machine for SHS casting was designed, which is an analog of a centrifugal carousel machine with a vertical axis of rotation (Fig. 3).

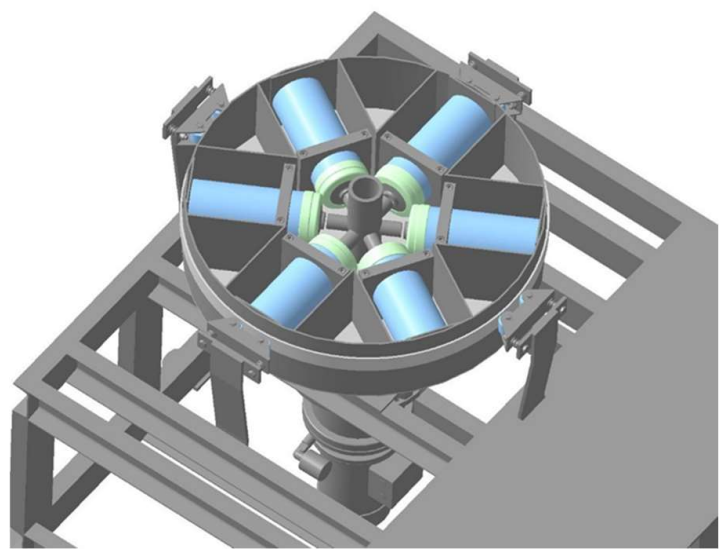

Figure 3: Centrifugal Machine for SHS Casting 
The launch of the centrifugal machine begins with the preparation of the reactor. The mold for casting and the lid are made of graphite, and the mold for casting consists of two half-molds for convenient extraction of the casting. Grooves are grooved in the connector plane of the half-molds and from the end sides to prevent leakage of liquid metal under pressure and violation of the integrity of the rotating assembly (Fig. 4)

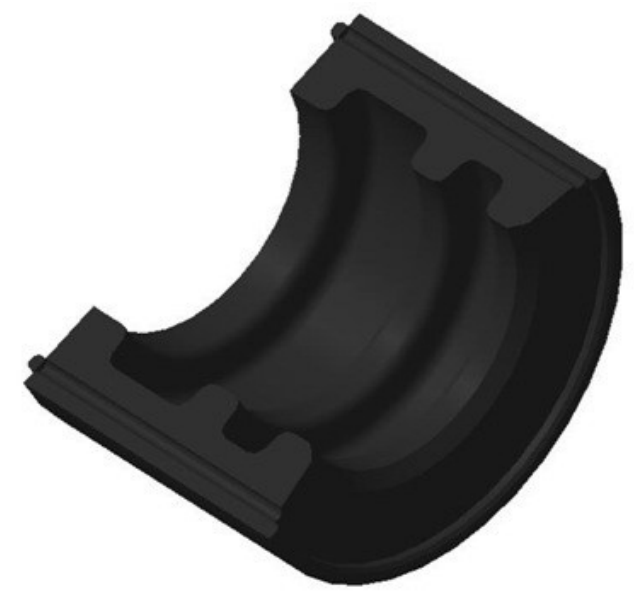

\section{Figure 4: Graphite Half-Mold for SHS Casting.}

The mold and the graphite reactor are lined with asbestos. Asbestos is a heater and prevents the contact of a nichrome spiral with the surface of a graphite reactor and a steel casing.

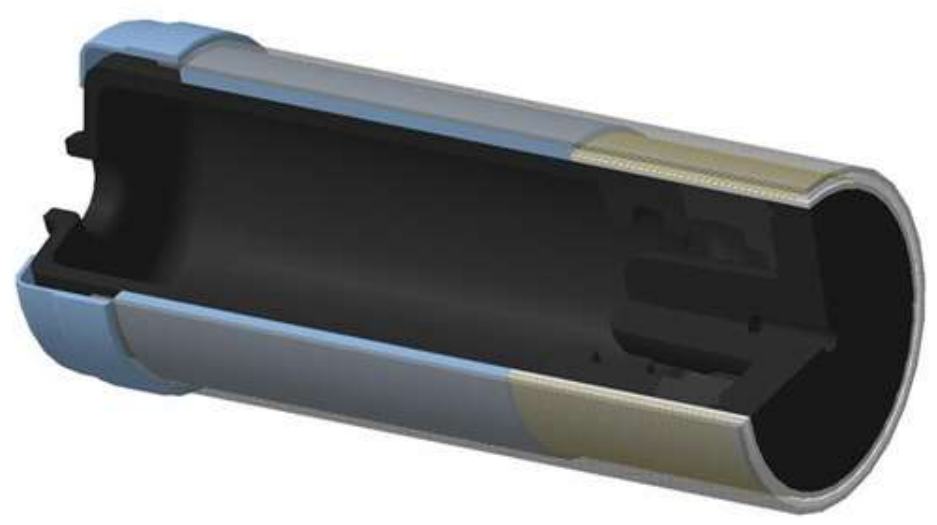

Figure 5: The Reactor Assembly.

The charge is loaded into the reactor manually. A mixture is placed in the lower part to initiate the SHS process, consisting of granular magnesium and potassium nitrate as an oxidizing agent, and the required amount of charge mixture is poured on top. Stiffening ribs in the form of plates are provided inside the drum, which forms an empty non-woven segment. 
This allows you to reduce the weight of the drum, thereby reducing the load on the bearings and increase the resource of the node as a whole. A gas outlet made of graphite is installed in the center of the drum. After assembly, the engine starts and through a planetary gear, the drum rotates at a speed of $5500 \mathrm{rpm}$ with a shoulder of $450 \mathrm{~mm}$. This ensures pressure under the influence of centrifugal forces, the acceleration of which exceeds that in a free fall of 100 times, i.e. overload of $100 \mathrm{~g}$ is provided.

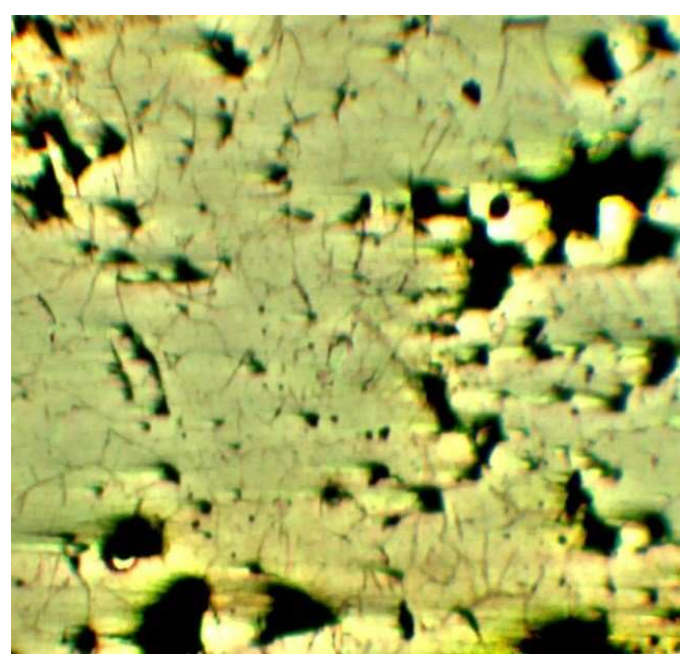

Figure 6: Microstructure of Castings in a Cast State

Figure 6 shows the microstructure of the obtained alloy. The microstructure photographs clearly show a large number of carbide inclusions of the $\gamma^{\prime}$-phase $\left(\mathrm{Fe}_{3} \mathrm{AlC}_{\mathrm{X}}\right)$ before annealing of the casting. During annealing (Fig. 7), carbide inclusions disintegrate and compact graphite inclusions form, which improves the mechanical and operational properties of the casting.

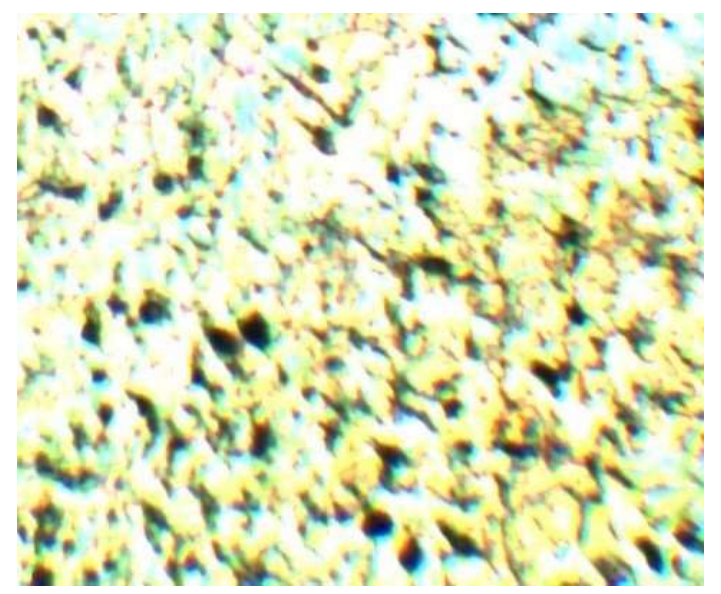

Figure 7: Microstructure of Castings After Isothermal Exposure

\section{Conclusions}

Thus, technology has been proposed for producing castings from aluminum cast iron with an aluminum content of 10 ... $19 \%$ by centrifugal SHS casting, they crystallize by a metastable mechanism, that is, in its structure carbon is in a bound state. The structure of these aluminum cast irons consists of two phases, namely: aluminum-doped ferrite and $\gamma^{\prime}$ phase, which is a carbide-type compound $\mathrm{Fe}_{3} \mathrm{AlC}_{\mathrm{X}}$. These phases are characterized by high hardness. The microhardness of ferrite is HV 360-400, and the microhardness of the $\gamma^{\prime}$ phase is even greater than HV 640-850. Due to the structural features of aluminum cast irons, they have high hardness and fragility, which is why they are unsuitable as a structural material. However, in view of the low density, which is $5600 \ldots 6000 \mathrm{~kg} / \mathrm{m}^{3}$, its use for cast parts helps to reduce their mass, which has a positive effect on the quality of automotive products. In addition, the discussed aluminum cast iron has heat resistance and wear resistance [2].

The proposed technology is environmentally friendly production and provides castings with high mechanical properties for structural materials comparing favorably with traditional aluminum cast iron smelting in high-frequency induction furnaces with a main lining, in which there are no traditional operations of loading pig iron and steel scrap into the furnace, and melting the charge, bringing liquid metal to a temperature of $1450-1500^{\circ} \mathrm{C}$ and alloying cast iron with aluminum by sinking it into the furnace to a full $\mathrm{p}$ Dissolution to reduce aluminum fumes. Research work has scientific novelty, and 
relevance, because solves an acute environmental problem; allows you to get useful and quality products in a non-waste mode

\section{Acknowledgments}

The work is performed according to the Russian Government Program of Competitive Growth of Kazan Federal University.

\section{References}

1. E.Ch. Gini, A.M. Zarubin, V.A. Rybkin. Foundry technology. Special types of molding: Textbook for universities. Edited by V. A. Rybkina. M .: Academia, - 2005 .- 350 pages.

2. V.N. Ivanov. Foundry Dictionary. - M.: Mechanical Engineering, 1990. - 384 pages.

3. N.N. Safronov, G.N. Safronov, L.R. Kharisov. SHS cast iron from dispersed wastes of mechanical engineering // Socio-economic and technical systems: research, design, optimization. - 2017. - No. 3 (76). - pp. 4-17.

4. N.N. Safronov, G.N. Safronov, L.R. Kharisov. Aluminum-Alloyed Cast Iron with Compact Graphite Inclusions from Fine Production Wastes // Russian Metallurgy (Metally). - Volume 2017, - Issue 13. - 2017. - pp.12071209.

5. N.N. Safronov, G.N. Safronov, L.R. Kharisov. SHS ferroaluminum obtained from the disperse waste of engineering // Material Science Forum. Volume 870. - 2016. - pp. 437-440. DOI: 10.4028 / www.scientific.net / MSF.870.437

6. G.N. Safronov, N.N. Safronov, L.R. Kharisov. (2015 The use of SHS-process slag for the preparation of foundry sand. J IOP Conference Series: Materials Science and Engineering 86: 1-4. doi: 10.1088 / 1757-899X / $86 / 1 / 012023$

7. N.N. Safronov, G.N. Safronov, L.R. Kharisov. The Corrosion-resistant high-silicon cast iron chemical engineering components / Chemical and Petroleum Engineering. - 2015. Vol. 51, Issue 1-2, pp. 142-144.

8. D.M. Yakovleva, G.F. Mukhametzyanova, L.R. Kharisov. The Research of Stresses in the Molds of Injection Molding Machines / Procedia Engineering, 2016 .- Vol. 150, pp. 453-457.

9. V.Ya. Safronov. Directory of foundry equipment. M.: Engineering, 1990. - 528 pages.

10. S.S. Zhukovsky, A.N. Boldin, etc. Foundry technology: molding and core mixtures / Textbook for high schools. - Bryansk: BSTU, 2002. - 470 pages. 